\title{
Dynamic Optimization of a Solar Thermal Energy Storage System over a 24 Hour Period using Weather Forecasts
}

Kody Powell

University of Texas at Austin

John Hedengren

Brigham Young University, john.hedengren@byu.edu

Thomas F. Edgar

University of Texas at Austin

Follow this and additional works at: https://scholarsarchive.byu.edu/facpub

Part of the Chemical Engineering Commons

\section{Original Publication Citation}

Powell, Kody M., John D. Hedengren, and Thomas F. Edgar. "Dynamic optimization of a solar thermal energy storage system over a 24 hour period using weather forecasts." 2013 American Control Conference. IEEE, 2013.

\section{BYU ScholarsArchive Citation}

Powell, Kody; Hedengren, John; and Edgar, Thomas F., "Dynamic Optimization of a Solar Thermal Energy Storage System over a 24 Hour Period using Weather Forecasts" (2013). Faculty Publications. 1714. https://scholarsarchive.byu.edu/facpub/1714 


\title{
Dynamic Optimization of a Solar Thermal Energy Storage System over a 24 Hour Period using Weather Forecasts
}

\author{
Kody M. Powell, John D. Hedengren, and Thomas F. Edgar, Member, AIChE
}

\begin{abstract}
A solar thermal power plant is used as a case study for dynamic heat integration with thermal energy storage. Findings show that thermal energy storage gives the system the ability to make the power dispatchable. Additionally, by solving a 24-hour dynamic optimization problem where the plant temperatures and power output are variable allows the system to capture and harvest a higher percentage of solar energy, with the most benefit occurring on mostly cloudy days. The solar energy captured increases $64 \%$ from 4.75 MWh to 7.80 MWh using this scheme. Hybrid plant operation and the ability to bypass the storage tanks further improve the system performance.
\end{abstract}

\section{INTRODUCTION}

$\mathrm{C}$ OONCERNS over global greenhouse gas emissions and limited fossil fuel supplies have led researchers and industry to pursue measures to increase energy efficiency and utilize renewable power sources. One of the major drawbacks to solar or wind energy is the intermittent nature of the supply. Energy storage allows an intermittent source of energy (such as wind or solar) to be harvested and redistributed in accordance with some demand schedule. Energy storage has also proven to be effective in enhancing traditional (fossil fuel) power sources by allowing these systems to shift times of production and consumption, giving them an increased ability to use their power generation capacity more effectively. As a result, a reduction in overall base-load power generation capacity can be achieved.

Thermal Energy Storage (TES) accumulates energy in one of its basest forms, as heat or cooling capacity (Dincer and Rosen, 2011). Typically, thermal energy storage involves storing energy by changing the temperature (sensible heat storage) or phase (latent heat storage) of some medium (which can be a fluid, solid, or a combination of both). It is this simplicity that makes TES such a promising technology. As an example, consider a set of processes where heat integration can be used to take waste heat from one process and deliver it to another, thereby reducing the need for supplemental energy. This idea works well if the processes

Manuscript received September 24, 2012. This work was supported in part by the National Science Foundation and the Cockrell School of Engineering at the University of Texas at Austin.

K. M. Powell is with the Chemical Engineering Department, University of Texas, Austin, TX 78712 USA, (phone: 512-471-5150; fax: 512-4717060; e-mail: powellk@che.utexas.edu).

J. D. Hedengren is with the Chemical Engineering Department, Brigham Young University, Provo, UT 84602 USA, (e-mail: john_hedengren@byu.edu).

T. F. Edgar is with the Chemical Engineering Department, University of Texas, Austin, TX 78712 USA, (e-mail: tfedgar@austin.utexas.edu). run at steady state for long periods of time. In fact, heat integration is typically considered only in steady state. Adding a TES system, however, gives the system flexibility to collect heat or cooling at one time and deliver it at a later time. This essentially gives the system extra degrees of freedom, which can lead to more optimal results. This idea applies well to systems with transient behavior, such as chemical plants with batch or semi-batch processes or power plants that undergo drastic changes in the availability of or demand for energy. In order to fully understand and optimize the performance of such systems, the dynamics of the problem must be considered. Because energy storage systems represent only one part of a greater energy system, it is critical to consider the entire system, and not the storage in isolation.

One case study that demonstrates dynamic heat integration is solar thermal power. Solar thermal plants use concentrated solar radiation to heat a fluid, which can be stored in a TES system and then delivered to a power block by creating steam. This system is inherently transient as the available solar energy goes through diurnal cycles as well as short-term fluctuations due to intermittent cloud cover (Gil et al, 2010). TES can be used to overcome each of these challenges, allowing the system to produce power constantly through cloud cover and even extend production into the night. TES can act as a buffer which turns an intermittent energy source into one that is dispatchable so that demands for power can be adequately met (Powell and Edgar, 2012).

The present work demonstrates that the performance of an energy system can be enhanced by operating the storage system based on the solution to a dynamic optimization problem for a time horizon of 24 hours. This requires a dynamic, systems-level model as well as the incorporation of forecasted values of externalities (e.g. weather-related parameters and energy demands). Allowing the plant to operate in hybrid mode, where multiple sources of energy can be used simultaneously, increases the degrees of freedom of the plant, which also leads to enhanced performance.

\section{Problem OvervieW}

\section{A. System Model}

1) Plant Description

Many of the ideas and methodology contained in this paper can be applied to a number of energy systems that use energy storage. However, the case study presented here focuses on a solar thermal power plant with storage and a 
backup source of energy, natural gas in this case. This particular system is interesting because it has a highly variable primary energy source (the sun) and an ability to operate over a wide range of conditions (variable flow rates and temperatures).

The configuration of the system under consideration is shown in Figure 1. The figure shows each component of the system and the streams (labeled 1-6) that connect each process. When sunlight is available, flow travels from the hot tank and enters the collector field, where parabolic mirrors are used to concentrate the sunlight onto an absorber pipe assembly. The hot fluid can then be collected into the hot storage tank or bypass the hot tank and go directly to the boiler. Fluid from the hot tank (stream 4) is mixed with the bypass fluid (stream 3 ) and used to heat the boiler. From the boiler fluid is returned to the cold tank. In order to maintain proper temperature control, another stream (6) is added which allows the fluid to bypass the boiler. It is assumed that this pipe is exposed to ambient air, so that it can effectively release excess heat when a full hot tank spills over through this line. An alternative approach is to divert parts of the collector field mirrors to prevent absorbing excess heat.

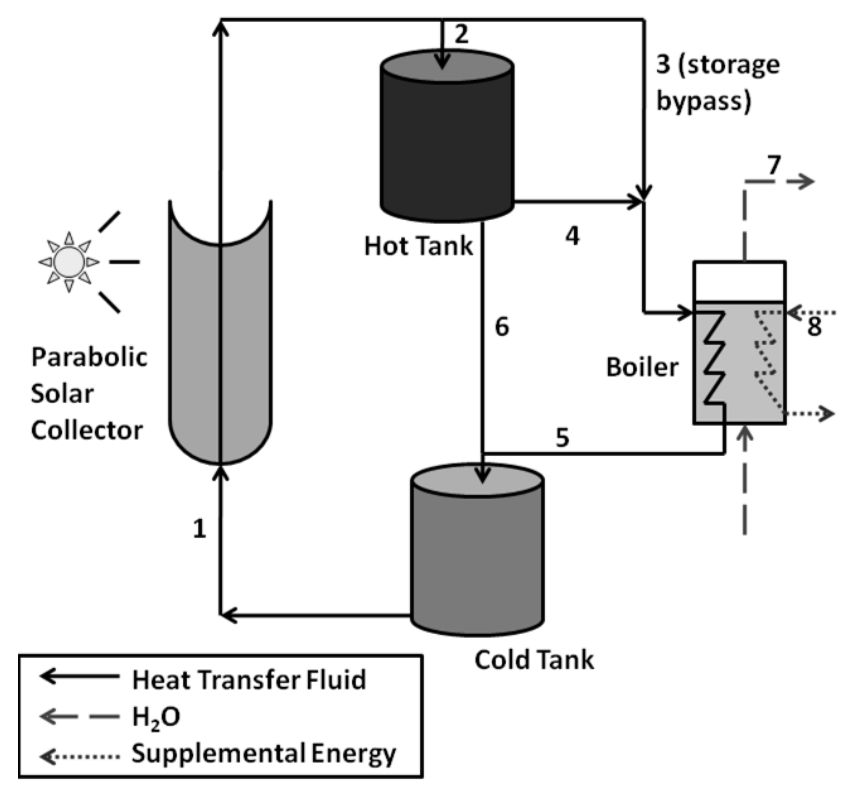

Figure 1: A schematic of the solar energy system with solar collector, storage tanks, and boiler.

2) Model and Optimization Overview

A dynamic model of the system is obtained by applying mass and energy conservation equations to each unit of the system. Details of the physical model can be found in previous works (Powell and Edgar, 2012). The model used here, however, is a DAE model of the entire system, so that multivariable control and optimization can be performed.

The model is simplified using model reduction and parameter estimation techniques that reduce the number of states used to describe the solar collector from 300 to 10 .

The system under consideration incorporates a relief pipe (stream 6), which allows the system to relieve excess heat to the environment in the event that the hot tank is full. This is used to prevent temperatures in the collector field from exceeding high temperature limits and allows for better temperature control. Another degree of freedom that is added is the ability to bypass the hot storage tank (stream 3), making it possible to store and deliver energy at different temperatures.

The general formulation for a dynamic nonlinear control or optimization problem is shown in Equation 1, where the vector $\mathbf{x}$ represents the differential states, $\mathbf{y}$, the algebraic states, $\mathbf{u}$, the manipulated variables, and $\mathbf{d}$, the exogenous disturbances. The vector-valued functions $\mathbf{f}$ and $\mathbf{g}$ represent the differential and algebraic process model, respectively, while $\mathbf{h}$ represents the inequality constraints of the system. The objective function is a scalar-valued function that can be adapted, depending on the desired application.

$$
\begin{aligned}
& \min _{u(t)} \int_{t=0}^{t=T} \phi(\mathbf{x}(\tau), \mathbf{y}(\tau), \mathbf{u}(\tau), \mathbf{d}(\tau)) d \tau \\
& \left.\begin{array}{l}
\frac{d \mathbf{x}}{d \tau}=\mathbf{f}(\mathbf{x}(\tau), \mathbf{y}(\tau), \mathbf{u}(\tau), \mathbf{d}(\tau)) \\
\mathbf{0}=\mathbf{g}(\mathbf{x}(\tau), \mathbf{y}(\tau), \mathbf{u}(\tau), \mathbf{d}(\tau)) \\
\mathbf{0} \geq \mathbf{h}(\mathbf{x}(\tau), \mathbf{y}(\tau), \mathbf{u}(\tau), \mathbf{d}(\tau))
\end{array}\right\} \tau \in[t=0, t=T]
\end{aligned}
$$

TABLE I

\begin{tabular}{|c|c|c|}
\hline Variables & Units & Description \\
\hline \multicolumn{3}{|c|}{ Differential State Variables $(\mathbf{x})$} \\
\hline $\mathrm{T}_{\mathrm{HT}}$ & $\mathrm{K}$ & Hot tank temperature \\
\hline $\mathrm{T}_{\mathrm{CT}}$ & $\mathrm{K}$ & Cold tank temperature \\
\hline $\mathrm{V}_{\mathrm{HT}}$ & $\mathrm{m}^{3}$ & Volume of fluid in hot tank \\
\hline $\mathrm{V}_{\mathrm{CT}}$ & $\mathrm{m}^{3}$ & Volume of fluid in cold tank \\
\hline $\mathrm{T}_{\mathrm{B}, 1}-\mathrm{T}_{\mathrm{B}, 5}$ & $\mathrm{~K}$ & $\begin{array}{l}\text { Temperature of spatially } \\
\text { discrete elements in boiler. }\end{array}$ \\
\hline $\mathrm{T}_{\mathrm{SC}, 1}-\mathrm{T}_{\mathrm{SC}, 10}$ & $\mathrm{~K}$ & $\begin{array}{l}\text { Temperature of spatially } \\
\text { discrete elements in solar } \\
\text { collector field. }\end{array}$ \\
\hline $\mathrm{T}_{\mathrm{R}}$ & $\mathrm{K}$ & Relief pipe temperature \\
\hline \multicolumn{3}{|c|}{ Algebraic State Variables $(\mathbf{y})$} \\
\hline$\dot{\mathrm{m}}_{2}$ & $\mathrm{~kg} / \mathrm{min}$ & Flow into hot tank \\
\hline$\dot{\mathrm{m}}_{4}$ & $\mathrm{~kg} / \mathrm{min}$ & Flow out of hot tank \\
\hline $\mathrm{T}_{\mathrm{J}}$ & $\mathrm{K}$ & $\begin{array}{l}\text { Temperature at junction of } \\
\text { stream } 3 \text { and stream } 4\end{array}$ \\
\hline Po & MW & Supplemental power needed \\
\hline \multicolumn{3}{|c|}{ Decision Variables (u) } \\
\hline$\dot{\mathrm{m}}_{1}$ & $\mathrm{~kg} / \mathrm{min}$ & Collector field flow rate \\
\hline$\dot{\mathrm{m}}_{3}$ & $\mathrm{~kg} / \mathrm{min}$ & Hot tank bypass flow rate \\
\hline$\dot{\mathrm{m}}_{5}$ & $\mathrm{~kg} / \mathrm{min}$ & Boiler flow rate \\
\hline$\dot{\mathrm{m}}_{6}$ & $\mathrm{~kg} / \mathrm{min}$ & Relief pipe flow rate \\
\hline \multicolumn{3}{|c|}{ Exogenous Disturbances $(\mathbf{d})$} \\
\hline $\mathrm{q}_{\mathrm{a}}$, & $\mathrm{W} / \mathrm{m}^{2}$ & Solar heat flux absorbed \\
\hline $\mathrm{T}_{\mathrm{a}}$ & $\mathrm{K}$ & Ambient temperature \\
\hline Vw & $\mathrm{m} / \mathrm{s}$ & Wind speed \\
\hline
\end{tabular}

DESCRIPTION OF MODEL VARIABLES

Table 1 defines the variables in the model. The differential model contains 28 total variables ( 24 differential 
and 8 algebraic), 4 of which are independent, leaving 4 manipulated (or decision) variables.

\section{B. Performance Improvements}

\section{1) Hybrid Plant Operation}

In order to increase dipatchability, power generation facilities that rely on intermittent renewable resources may have a built-in backup source of fuel, typically fossil fuel. When the backup source of energy is coal, power plants often take hours to start-up or shutdown power generation. Having energy storage capability can help balance base-load availability. In the case of solar thermal power, this backup fuel is typically natural gas, giving the system the ability to make up for shortfalls of power when enough solar energy is not available. These backup systems typically operate reactively and may only turn on when a shortage of power is imminent. However, when a proactive approach is taken, predictions of future plant performance can be used to dispatch the backup power more efficiently. Using the example of solar thermal power, when less sunlight is anticipated, it is optimal to deliver heat at a lower temperature. The lower temperature may negatively affect the plant's ability to deliver the full load of power in the short term. However, operating at a lower temperature reduces radiative and convective losses in the solar collector field, enabling the solar component to deliver more energy over the course of the entire day.

When considering the delivery of heat to a load at different temperatures, one may also consider a means to bypass the storage system. This allows energy to be stored at one temperature, but then delivered to the load at a different temperature if the storage is bypassed temporarily.

\section{2) Forecasts}

A proactive approach to plant operation requires the ability to accurately predict over the desired time horizon. If the system depends heavily on external factors, such as energy availability or demand, these factors should be included in the prediction. The case study of solar thermal power requires predictions of available solar energy over the course of a day in order to solve this dynamic optimization problem. Forecasting of weather and solar radiation in particular is an inexact science, which gives rise to uncertainty. Uncertainty makes it difficult to reliably predict plant performance, regardless of the accuracy of the plant model. However, it may be argued that some information, while imperfect, is better than a complete lack of information. Additionally, certain aspects of solar radiation can be predicted with more precision. For example, the maximum radiation available at a given time for a given location is based largely on geometric relationships between the earth and the sun. These relationships are well-known and affect the sunrise and sunset time for the location, which is known with precision. Furthermore, many solar thermal plants are located in regions with little cloud cover, in which case, the solar radiation will largely be a function of the time of day and year.
For the general case in which cloud cover is expected, technologies have been developed to deliver reasonably accurate short-term predictions of solar radiation, based on available information from general weather forecasts. Marquez and Coimbra used stochastic learning methods to take short term weather forecast data from the U.S. National Weather Service forecasting database and develop empirical models for predicting both global horizontal irradiance (GHI) and direct normal irradiance (DNI) for up to several days in advance. Their predictions were compared to measured values and performed reasonably well with relative root mean square error (rRMSE) ranging from 15 $22 \%$ for GHI and 28-35\% for DNI for same-day forecasts (Marquez and Coimbra, 2011). Because concentrating solar thermal power plants rely mainly on DNI, there is concern with the higher error in forecasting for DNI. Nevertheless, it is anticipated that, since this is a new area of research, the accuracy of these forecasts will improve.

Due to the uncertainty that arises in using weather forecasts for dynamic optimization of energy systems, one should consider the stochastic nature of the problem. Zavala et al. discuss a methodology for solving stochastic dynamic real-time optimization (D-RTO) problems, based on assuming some probability distribution, generally Gaussian. Here it is recommended that hierarchical control be used, where Manipulated Variables (MVs) in the D-RTO problem are used as set-points and delivered to lower level controller to achieve these set-points. (Zavala et al., 2009). For the case study of the solar thermal plant presented here, the problem is treated as a deterministic manner, assuming that the solar irradiance forecasts are perfect; therefore, solving the problem as a hierarchical control problem is unnecessary. For real implementations of the proposed control structure, it is proposed that this hierarchical structure be used with temperature set-points as decision variables on the supervisory level and on a longer time scale (hours) using lower-level Nonlinear Model Predictive Control (NMPC) to maintain those set-points. This methodology will provide the plant with stability as it can make short term control moves to overcome disturbances on a smaller time scale (minutes).

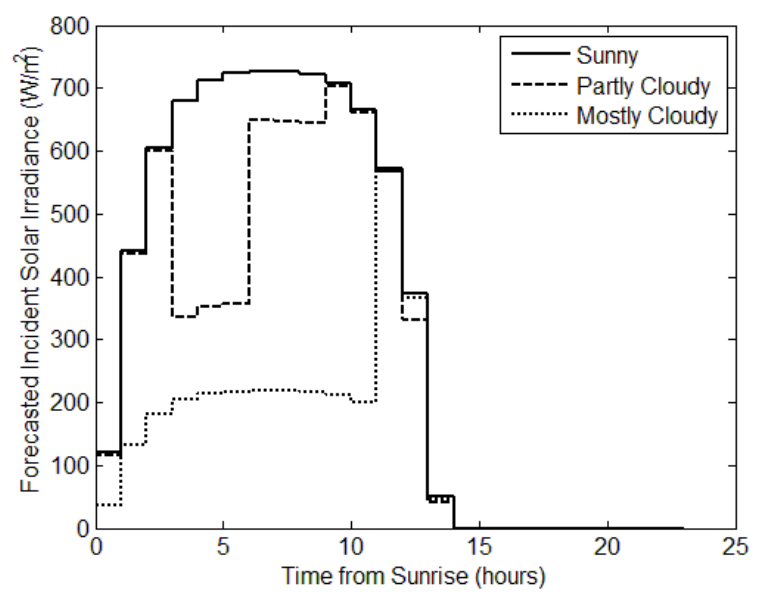

Figure 2: Hourly-averaged direct normal solar irradiance values used for three scenarios. 


\section{RESULTS}

\section{A. Temperature and Power Control with NMPC}

The typical solar plant operating strategy is to maintain a constant outlet temperature for the solar collector field (Camacho et al., 2007). Adding a thermal energy storage system provides the added benefit of being able to maintain a constant power output from the plant. This operating strategy is replicated using an MPC approach. The objective function uses the L1 norm to keep the solar field outlet temperature and plant power output within a dead-band, given that the resources are available at the time to do so. The L1 Norm has advantages over an L2 or squared error objective. These advantages include no additional nonlinear equations or objective terms, ability to specify a controlled variable dead-band, and prioritization of controlled variables. One drawback of the L1-norm objective is that there are additional slack variables and equation inequalities that need to be solved simultaneously with the model equations. The form of the objective function is shown below, where $\mathrm{Q}_{1}$ and $\mathrm{Q}_{2}$ are weighting coefficients.

$$
\begin{aligned}
& \min _{u(t)} \int_{t=0}^{t=\Delta t}\left[Q_{1} \max \left\{\left(T_{S C, 10}-T_{S P, l o}\right),\left(T_{S P, h i}-T_{S C, 10}\right)\right\}+\right. \\
& \left.Q_{2} \max \left\{\left(P_{o, \text { solar }}-P_{S P, l o}\right),\left(P_{S P, l o}-P_{o, \text { solar }}\right)\right\}\right] d \tau
\end{aligned}
$$

As Figure 3 shows, NMPC maintains a constant temperature, despite fluctuations in available solar energy. This approach assumes real-time measurements of DNI, which gives the controller the ability to react immediately to changes in solar radiation, without having to rely solely on feedback control.

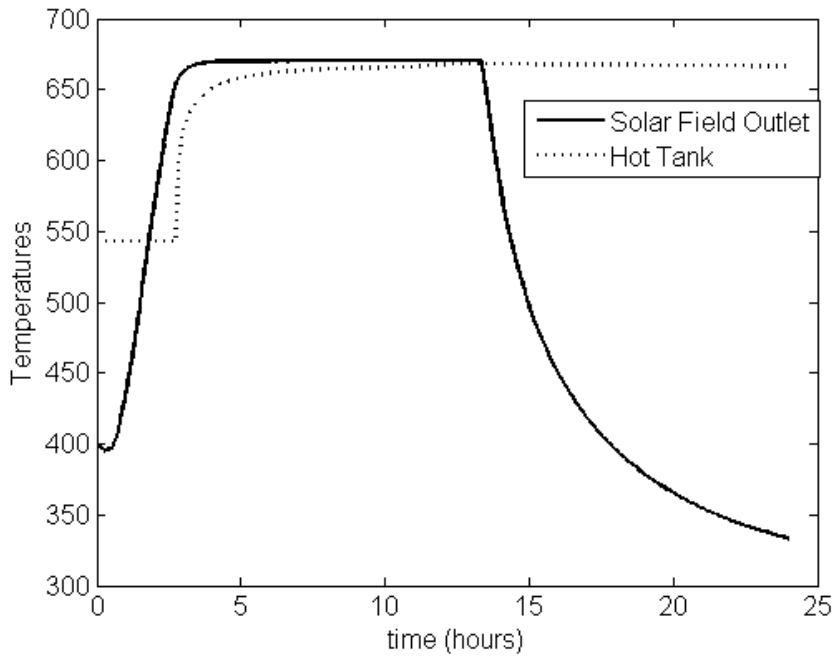

Figure 3: Temperatures v. time for the constant temperature/constant power approach.

Figure 4 illustrates that the NMPC combined with thermal energy storage allows the plant to deliver power at a constant rate, despite fluctuations in available solar energy. The power control cannot be activated until there is sufficient energy stored so sustain power for several hours.
In the case of a mostly cloudy day, this requires waiting until 10 hours from sunrise to turn on this controller.

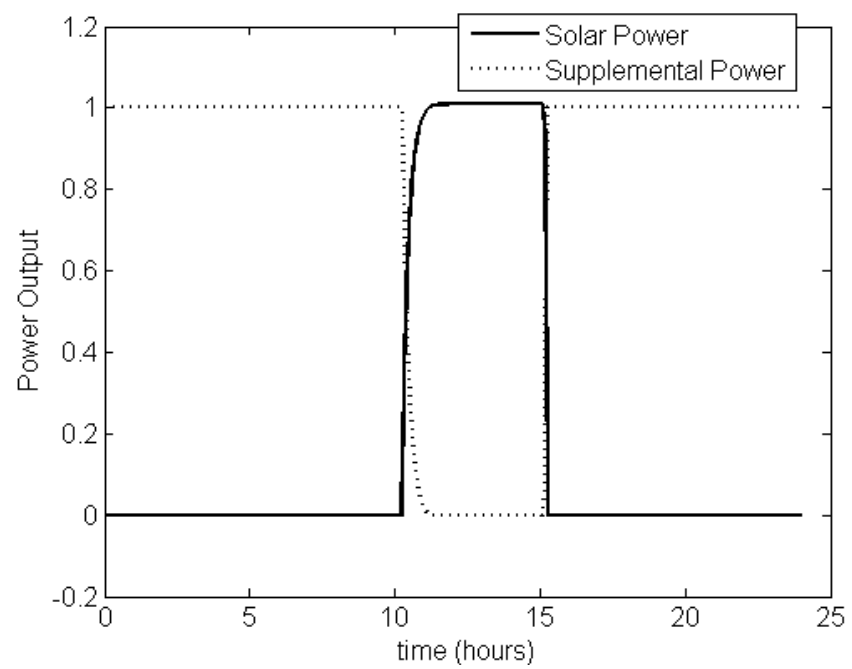

Figure 4: Power v. time for the constant temperature/constant power approach.

Due to the limited availability of solar radiation for the first several hours of the day, mass flow rates must be kept very low in order to heat up to the required control temperature. This increases the residence time in the solar field, which, in combination with the high temperatures, leads to large radiation losses. Mass flow rates increase fairly rapidly after the cloud cover passes and more radiation is available. This is necessary to keep the temperature at the desired setpoint.

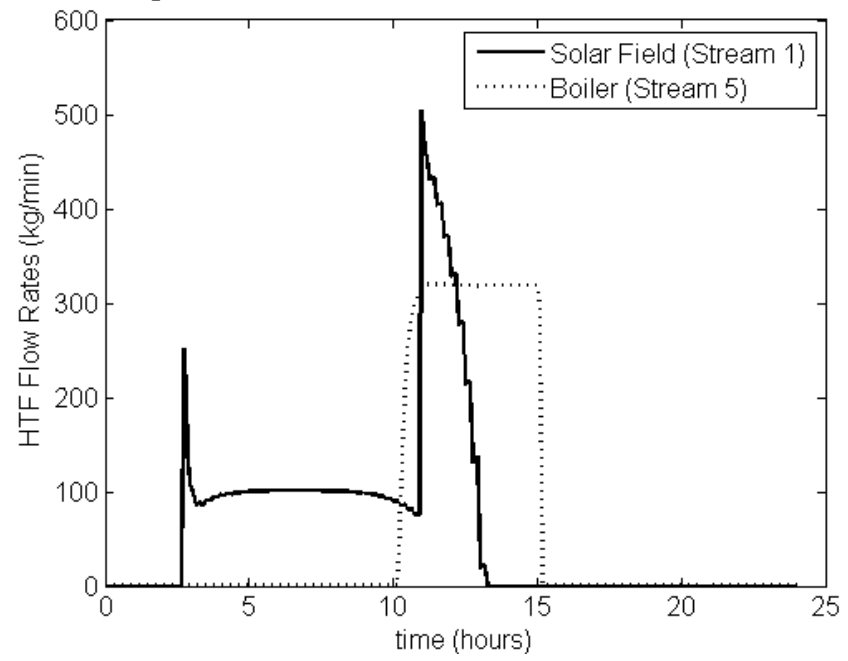

Figure 5: Mass flow rates v. time for the constant temperature/constant power approach.

Additionally, large storage volumes cannot be reached, giving the system little ability to extend power production after sunset. The system reaches only a third of its total storage capacity, so that power production only continues for 1-2 hours after sunset until the storage volume is depleted during hour 14. 


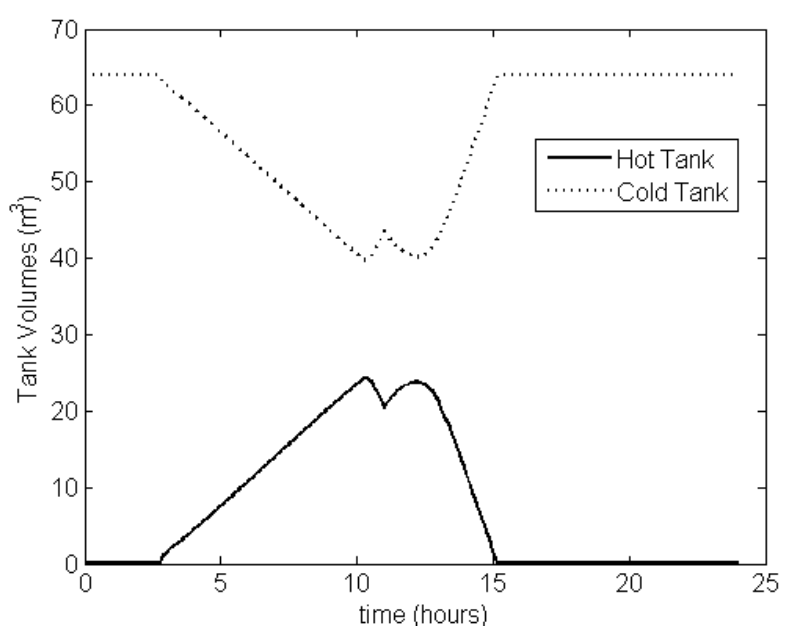

Figure 6: Storage tank volumes v. time for the constant temperature/constant power approach.

\section{B. Dynamic Optimization with Forecast}

The dynamic optimization strategy uses a day-ahead forecast of the available DNI with the objective to minimize the total supplemental energy used over the course of the day. The power requirement for the plant remains constant at $1 \mathrm{MW}_{\text {th }}$ and it is assumed that the supplemental energy source accounts for any shortfalls form the solar energy side. The objective function is as follows, with Po being the supplemental power rate:

$$
\min _{u(t)} \int_{t=0}^{t=T}(P o) d \tau
$$

Operating the plant with this optimization objective allows the plant to control to optimal temperatures, rather than constant temperatures. As Figure 7 shows, the optimization routine has determined that it is optimal to control to lower temperatures, given that less solar energy is available on the mostly cloudy day under consideration. There are, however, times when higher temperatures are optimal.

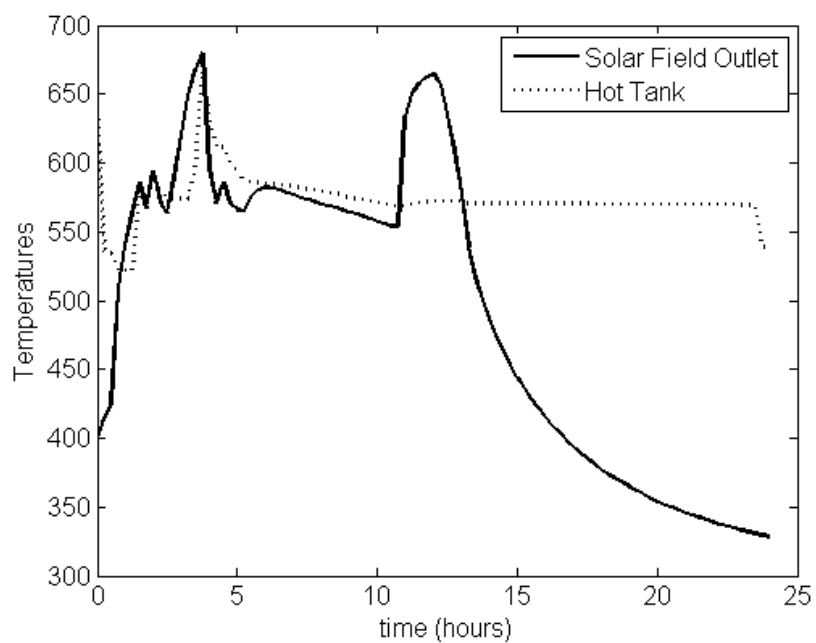

Figure 7: Temperatures v. time with the dynamic optimization approach.
In conjunction with the lower field temperatures, the optimal solar power output is generally less than the full load. It is notable, however, that as the day transitions from mostly cloudy to sunny just before sunset, the solar power shifts briefly to providing the full load of $1 \mathrm{MW}_{\text {th }}$. This occurs largely during hours 11 and 12 of the simulation. This occurs because the system is able to reach higher temperatures without having to drastically reduce flow rates. Therefore, higher temperature energy can be delivered to the power block, which is sufficient to provide the full load.

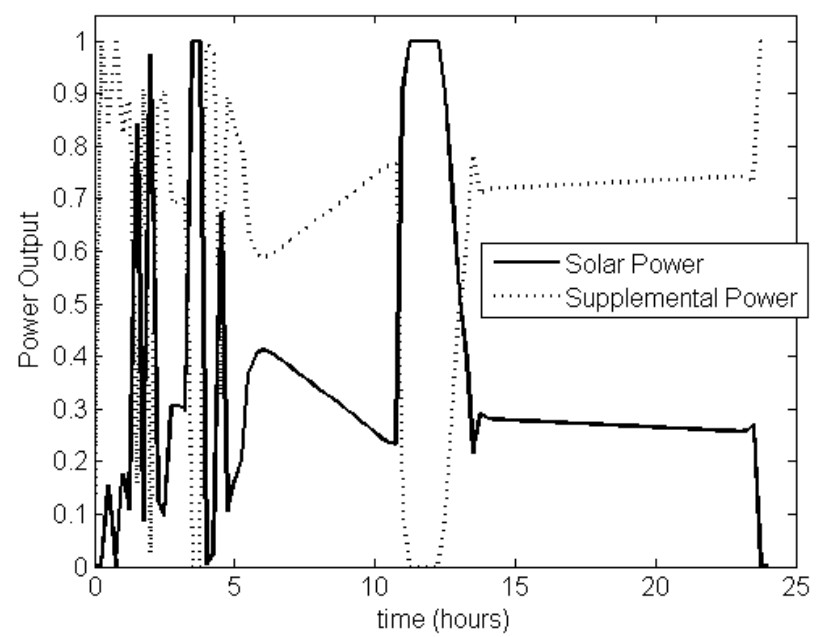

Figure 8: Solar and supplemental power v. time for the dynamic optimization approach.

During this time of full-load solar production, the mass flow bypasses the hot storage tank almost entirely. Figure 9 shows this with the flows of streams 1,3 , and 5 being relatively equal. This illustrates the value of the ability to bypass storage. The fluid can be stored at the lower temperature during cloudy operation. Then when higher temperatures are optimal, the storage can be bypassed to prevent the entropy generation that would occur from mixing the fluid at different temperatures together.

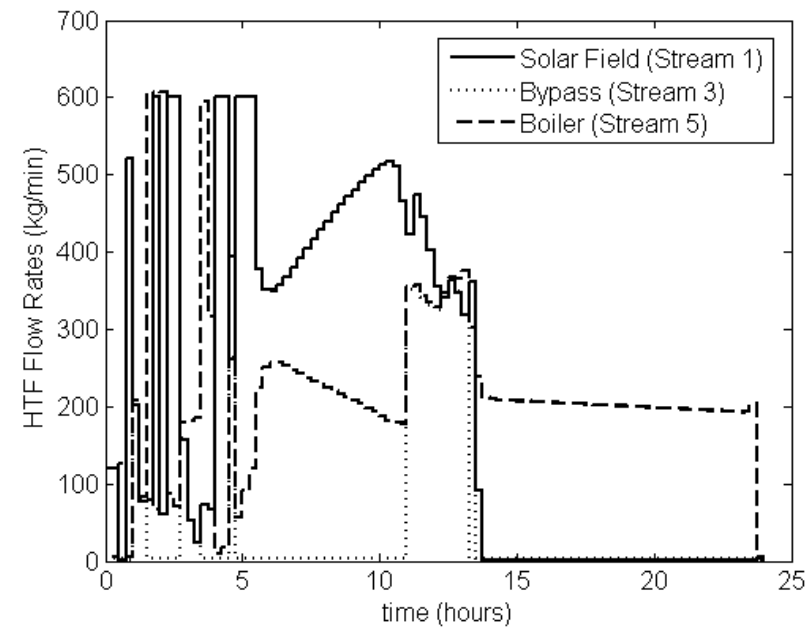

Figure 9: Mass flow rates v. time for the dynamic optimization approach.

At the end of the day, the hot tank, full of lower temperature fluid, is then used until the end of the time horizon ( $\mathrm{t}=\mathrm{T}=24$ hours) to provide roughly $30 \%$ of the total load. Thus, the ability for the system to provide only a 
partial load during times of cloud cover proves beneficial. This allows the system to continuously produce solar energy for nearly the entire 24 hour period. By keeping the temperatures generally lower during periods of cloud cover, radiative losses are reduced, resulting in a greater benefit of the solar energy.

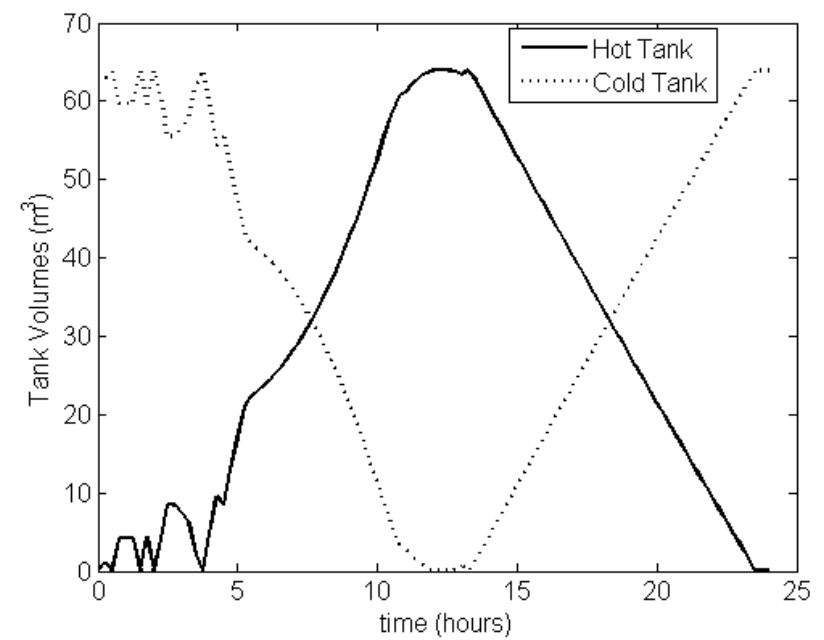

Figure 10: Storage tank volumes v. time for the dynamic optimization approach.

\section{Summary}

By including forecasted solar radiation and solving the dynamic optimization problem over a 24-hour time horizon, results are improved for all three scenarios explored. Because of the ability to reduce radiative heat losses during cloudy days, the results for these days are the most promising.

TABLE II

SUMMARY OF RESULTS

\begin{tabular}{lll}
\hline & $\begin{array}{l}\text { Solar } \\
\text { Energy } \\
\text { Collected } \\
\text { (MWh) }\end{array}$ & $\begin{array}{l}\text { Energy } \\
\text { Collected/ } \\
\text { Total Incident } \\
\text { Energy (\%) }\end{array}$ \\
\hline Sunny Day & 18.02 & $76.8 \%$ \\
\hline $\begin{array}{l}\text { Constant Temperature/ } \\
\text { Load Control }\end{array}$ & 18.59 & $79.2 \%$ \\
$\begin{array}{l}\text { Dynamic Optimization } \\
\text { w/ Forecast }\end{array}$ & 14.60 & $74.8 \%$ \\
\hline Partly Cloudy Day & & \\
\hline $\begin{array}{l}\text { Constant Temperature/ } \\
\text { Load Control }\end{array}$ & 15.83 & $81.1 \%$ \\
$\begin{array}{l}\text { Dynamic Optimization } \\
\text { w/ Forecast }\end{array}$ & & \\
\hline Mostly Cloudy Day & & \\
\hline $\begin{array}{l}\text { Constant Temperature/ } \\
\text { Load Control }\end{array}$ & 4.75 & $85.4 \%$ \\
$\begin{array}{l}\text { Dynamic Optimization } \\
\text { w/ Forecast }\end{array}$ & 7.80 & \\
\hline
\end{tabular}

\section{CONCLUSIONS}

Thermal energy storage provides a simple, inexpensive way to better align times of energy availability with times of energy demand. This provides a means for dynamic heat integration, where excess energy generated at one time can be saved and delivered to a heat sink at a later time. This idea opens up many opportunities for optimal control schemes.

Solar thermal power provides an interesting case study for the idea of dynamic heat integration. It is a process that is inherently transient and cyclical. By performing dynamic optimization over a 24 hour period, it has been shown that the plant can be operated differently under different weather conditions to achieve optimal results for each condition. This requires using weather forecasts. While these forecasts have uncertainties, there are operational strategies that can be used to minimize the negative effects of the uncertainties. One such strategy is dynamic real-time optimization, where the dynamic optimization acts as a supervisory controller, providing setpoints (temperature and power) and feeding these setpoints to lower-level NMPC controllers. This strategy will allow the plant to operate with stability during short bursts of cloud cover. Additionally, the optimization problem can be solved on an hourly or bi-hourly basis as new information (plant states, actual DNI and updated forecasts) becomes available.

\section{REFERENCES}

[1] A.Gil, M. Medrano, I. Martorell, A. Lazaro, P. Dolado, B. Zalba, and L. Cabeza, "State of the art on high temperature thermal energy storage for power generation. Part 1-Concepts, materials, and modellization," Renewable and Sustainable Energy Reviews, vol. 14, pp. 31-55, 2010.

[2] E.F. Camacho, F.R. Rubio, M. Berenguel, L. Valenzuela, "A survey on control schemes for distributed solar collector fields. Part I: Modeling and basic control approaches," Solar Energy, vol. 81, pp. 1240-1251, 2007.

[3] E.F. Camacho, F.R. Rubio, M. Berenguel, L. Valenzuela, "A survey on control schemes for distributed solar collector fields. Part II:Advanced control approaches," Solar Energy, vol. 81, pp. 12521272, 2007.

[4] I. Dincer and M.A. Rosen, Thermal Energy Storage Systems and Applications, 2nd ed. West Sussex, UK: Jon Wiley and Sons, 2011.

[5] K.M. Powell and T.F. Edgar, "Modeling and Control of a Solar Thermal Plant with Thermal Energy Storage," Chemical Engineering Science, vol. 71, pp. 138-145, 2012.

[6] R. Marquez and C.F.M. Coimbra, "Forecasting of global and direct solar irradiance using stochastic learning methods, ground experiments, and the NWS database," Solar Energy, vol. 85, pp. 746$756,2011$.

[7] V.M. Zavala, E.M. Contantinescu, T. Krause, and M. Anitescu, "Online economic optimization of energy systems using weather forecast information," Journal of Process Control., vol. 19, pp. 1725-1736, 2009. 